\title{
Influência do sexo e idade de abate sobre rendimento de carcaça e qualidade da carne de codornas de corte
}

\author{
Carcass evaluation and meat quality of slaughtered meat quails at different ages
}

\author{
ABREU, Luiza Rodrigues Alves ${ }^{1 *}$; BOARI, Cleube Andrade ${ }^{2}$; PIRES, Aldrin Vieira ${ }^{2}$; \\ PINHEIRO, Sandra Regina Freitas ${ }^{2}$; OLIVEIRA, Renata Gomes de ${ }^{3}$; OLIVEIRA, \\ Kênia Maria de ${ }^{1}$; GONÇALVES, Flaviana Miranda ${ }^{3}$; OLIVEIRA, Felipe Rosa ${ }^{1}$
}

\footnotetext{
${ }^{1}$ Universidade Federal dos Vales do Jequitinhonha e Mucuri, Programa de Pós-Graduação em Zootecnia, Diamantina, Minas Gerais, Brasil.

${ }^{2}$ Universidade Federal dos Vales do Jequitinhonha e Mucuri, Departamento de Zootecnia, Diamantina, Minas Gerais, Brasil.

${ }^{3}$ Universidade Federal de Minas Gerais, Programa de Pós-Graduação em Zootecnia, Belo Horizonte, Minas Gerais, Brasil.

*Endereço para correspondência: luizabreu@zootecnista.com.br
}

\section{RESUMO}

O trabalho foi conduzido com o objetivo de se avaliar o efeito de duas idades de abate sobre o rendimento de carcaça e propriedades finais da carne de codornas de corte (Coturnix coturnix). Foram abatidas 40 codornas (machos e fêmeas) aos 35 e aos 42 dias de idade obtendo-se o peso corporal, peso de carcaça quente e resfriada, peso de peito, peso de perna, rendimento de carcaça quente e fria, rendimento de peito, rendimento de pernas, $\mathrm{pH}$ inicial e final (24 horas "post mortem", capacidade de retenção de água (CRA), cor $\left(L^{*}, a^{*}, b^{*}\right)$, perda de peso por cocção (PPC) e maciez objetiva (força de cisalhamento). Não houve diferença no rendimento de carcaça e cortes entre as idades de abate, entretanto as aves abatidas aos 42 dias de idade apresentaram-se com maior peso corporal. Para os parâmetros da qualidade da carne, observou-se que o $\mathrm{pH}$ inicial foi menor para as aves abatidas aos 42 dias de idade. Fêmeas abatidas aos 35 dias de idade apresentaram carne com menor teor de vermelho. Machos apresentaram a carne com $\mathrm{pH}$ mais baixo. Dessa forma o abate dos animais aos 42 dias de idade proporcionou melhor desempenho e melhores características de carcaça aos machos.

Palavras-chave: cor, maciez objetiva, $\mathrm{pH}$

\section{SUMMARY}

The objective of this work was to evaluate the effect of sex and two ages at slaughter on the performance, carcass traits and meat quality of quails (Coturnix coturnix). Forty quails (males and females) were slaughtered at an age of 35 and 42 days. Then, the body weight, hot and cold carcass weight, breast weight, leg weight, hot and cold carcass yield, breast yield, leg yield, initial and final (24 hours post-mortem) $\mathrm{pH}$ values, water-holding capacity (WHC), color ( $\mathrm{L}^{*}, \mathrm{a}^{*}$ and $b^{*}$ ), cooking loss and objective tenderness (shear force) were evalauted. There were no differences in carcass and cuts yields between the ages at slaughter. However, the quails slaughtered at 42 days of age had higher body weight than the quails slaughtered at 35 days of age. As to the parameters of meat quality, the initial $\mathrm{pH}$ values were lower in quails slaughtered at 42 days of age than in quails slaughtered at 35 days of age. Females slaughtered at 35 days of age had meat with lower degree of redness. The $\mathrm{pH}$ values of meat from males were lower with regard to those ones of meat from females. Therefore, the slaughter at 42 days of age yielded a better performance and carcass traits in males quails.

Keywords: carcass yield, color, $\mathrm{pH}$ 


\section{INTRODUÇÃO}

A coturnicultura tem despertado grande interesse por parte dos produtores uma vez que o espaço para criação é relativamente pequeno e a demanda de investimentos é baixa (OLIVEIRA et al., 2002a).

A produção de carne de codornas foi, por longo período, caracterizada pelo abate de aves provenientes das criações destinadas à produção de ovos, da qual alguns machos erroneamente classificados no processo da sexagem e criados até os 42 ou 49 dias de idade, ou fêmeas ao fim do primeiro ciclo de produção de ovos eram abatidas (GARCIA, 2002). Como consequência, as carcaças provenientes do abate de machos apresentavam menor tamanho e a carne provinda do abate das fêmeas era relativamente dura, por se tratar de aves mais velhas. Fatores que certamente contribuíram para que a aceitação da carne de codorna pelo mercado consumidor fosse aquém do seu potencial.

Com a utilização de linhagens específicas para corte, a produtividade e qualidade da carne têm melhorado significativamente, o que se associa ao crescente aumento na demanda mundial por este produto. Entretanto, mesmo com os avanços na área do melhoramento genético e manejo alimentar destes animais, há constante necessidade de se pesquisar sobre efeitos de manejo e sexo sobre o rendimento de carcaça e qualidade da carne, com a finalidade de se embasar a tomada de decisões acerca do manejo zootécnico das codornas de corte.

Dentre as características de qualidade da carne de codornas, a coloração é de extrema importância para a boa aceitação por parte do mercado consumidor. A carne de codornas é um pouco mais escura que a do frango de corte e os principais fatores que interferem nesta coloração são a idade, o sexo, a atividade do músculo (mioglobina) e alimentação. A qualidade da carne depende ainda da temperatura do tecido muscular e da velocidade de resfriamento após o abate, sendo que as velocidades das reações bioquímicas são reduzidas em baixas temperaturas (VIEIRA et al., 1999).

Neste contexto, a pesquisa sobre a qualidade da carne de codornas deve considerar a avaliação de rendimento de carcaça e cortes, maciez, $\mathrm{pH}$, capacidade de retenção de água, perda de peso por cozimento, cor e luminosidade, os quais mantém relação estreita com a sua aceitação por clientes e consumidores (GENCHEV et al., 2005).

Considerando-se o exposto, a pesquisa foi realizada com o objetivo de se avaliar o efeito da idade de abate e do sexo sobre o rendimento de carcaça e qualidade da carne de codornas de corte.

\section{MATERIAL E MÉTODOS}

Foram utilizadas aves provenientes de uma linhagem de codornas de corte (Coturnix coturnix) denominada LF1, pertencente ao Programa de Melhoramento Genético de Codornas do Departamento de Zootecnia da Universidade Federal dos Vales do Jequitinhonha e Mucuri, em Diamantina/MG. Os ovos utilizados para incubação foram provenientes de matrizes da mesma idade e igual condição de manejo.

As codornas utilizadas nas análises foram amostradas aleatoriamente aos 35 e aos 42 dias de idade, sendo 10 machos e 10 fêmeas com 35 dias de idade, 10 
machos e 10 fêmeas com 42 dias de idade. As codornas foram retiradas de uma população de 1.528 codornas que foram criadas do nascimento ao $42^{\circ}$ dia de idade em boxe com piso de concreto e cama de maravalha com campânulas de aquecimento, utilizadas até os 21 dias de idade. As aves receberam ração e água a vontade, sendo que do nascimento ao $21^{\circ}$ dia a ração continha $25 \% \mathrm{~PB}$ e $2900 \mathrm{kcal}$ de $\mathrm{EM} / \mathrm{kg}$ e do $22^{\circ}$ ao $42^{\circ}$ dia a ração foi formulada contendo $24 \%$ de PB e 2925 kcal de $\mathrm{EM} / \mathrm{kg}$, segundo informações de exigências nutricionais da literatura (OLIVEIRA et al., 2002b; FRIDRICH et al., 2005; CORRÊA et al., 2007; SILVA, 2009; VELOSO et al., 2010; VELOSO et al., 2012). As rações foram formuladas conforme as informações de composição nutricional descritas por Rostagno et al. (2011).

As aves foram submetidas a jejum alimentar de 6 horas, sendo transportada uma hora antes do abate para a sala de abate, provida de luz azul, em seguida pesadas e insensibilizadas por deslocamento cervical e abatidas, realizando-se a sangria, por 3 minutos. As aves foram escaldadas em temperatura de 52 a $54^{\circ} \mathrm{C}$ por 60 a 80 segundos, depenadas, evisceradas, pesadas e resfriadas. As amostras permaneceram 24 horas armazenadas à temperatura de aproximadamente $2^{\circ} \mathrm{C}$.

As análises de qualidade da carne foram realizadas no Setor de Ciências e Tecnologia dos Produtos de Origem Animal, do DZO/UFVJM.

As variáveis analisadas foram: peso corporal, peso e rendimento de carcaça quente e resfriada, peso e rendimento do peito, peso e rendimento das pernas, queda de $\mathrm{pH}$ 'post mortem', $\mathrm{pH}$ inicial, $\mathrm{pH}$ final, capacidade de retenção de água, perda de peso por cozimento, cor e luminosidade $\left(L^{*}, a^{*}, b^{*}\right)$ e maciez objetiva.
Para determinação do $\mathrm{pH}$ inicial e final utilizou-se o potenciômetro composto de um eletrodo de penetração, inserido diretamente no músculo Pectoralis major. A capacidade de retenção de água (CRA) foi realizada utilizando a metodologia descrita por Hamm (1960). A cor dos peitos foi determinada por uso de colorímetro (Minolta), no sistema CIELAB, sendo avaliados os parâmetros L* (luminosidade), a* (teor de vermelho) e $b^{*}$ (teor de amarelo). Essa avaliação foi feita conforme metodologia proposta por Van Laack et al. (2000).

Para as análises da perda de peso por cozimento, amostras de filés íntegros foram embaladas em papel laminado, sendo cozidas em uma chapa metálica de dupla face, com aquecimento em ambas as faces, pré-aquecida e regulada para $180^{\circ} \mathrm{C}$, permanecendo por 4 minutos para cada lado do filé, totalizando 8 minutos de cozimento ou até atingir uma temperatura interna de 82 a $85^{\circ} \mathrm{C}$. Após o cozimento, os filés foram retirados do papel laminado e resfriados sobre papel absorvente à temperatura ambiente. Posteriormente, as amostras foram pesadas para averiguação da perda de peso antes e após cozimento. A diferença entre o peso inicial (peito "in natura") e final (peito cozido) correspondeu à perda de peso por cozimento (HONIKEL, 1987).

Para a avaliação da maciez objetiva (força de cisalhamento) foi utilizado o texturômetro Stable Micro Systems TAXT 2 plus, equipado com probe blade set $\mathrm{V}$ Warner Bratzler. $\mathrm{O}$ equipamento foi calibrado com pesopadrão de $5 \mathrm{~kg}$ e padrão rastreável. A velocidade de descida e corte do dispositivo foi ajustado a $200 \mathrm{~mm} \mathrm{~min}^{-1}$ (AMSA, 1995). As amostras utilizadas foram as mesmas da determinação da perda de peso por cozimento. Foram retiradas três amostras por filé de peito 
na forma de paralelepípedos com 1 x 1 x $2 \mathrm{~cm}$ (altura, largura e comprimento, respectivamente), as quais foram colocadas com as fibras orientadas no sentido perpendicular à lâmina da probe Warner-Blatzler.

As análises estatísticas foram realizadas utilizando-se o software SAS version 6.0 (STATISTICAL ANALYSES SYSTEM, 1996) considerando-se um delineamento inteiramente casualisado em esquema fatorial (dois sexos $\mathrm{x}$ duas idades de abate) com 10 repetições.

\section{RESULTADOS E DISCUSSÃO}

Houve interação $(\mathrm{P} \leq 0,05)$ entre o sexo e a idade das codornas de corte para teor de vermelho (Tabela 1).

Tabela 1. Interação sexo X idade de codornas européias, machos e fêmeas, abatidas aos 35 e 42 dias

\begin{tabular}{lcccc}
\hline \multirow{2}{*}{ Parâmetro } & \multirow{2}{*}{ Sexo } & \multicolumn{2}{c}{ Idade de abate } & \multirow{2}{*}{ CV(\%) } \\
\cline { 3 - 4 } & & 35 dias & 42 dias & \multirow{2}{*}{ Macho } \\
\multirow{2}{*}{ Teor de vermelho $\left(\mathrm{a}^{*}\right)$} & $10,89 \pm 1,13$ & $10,69 \pm 1,17$ & \multirow{2}{*}{10,27} \\
& Fêmea & $9,58 \pm 0,91^{\mathrm{b}}$ & $11,52 \pm 1,16^{\mathrm{a}}$ & \\
\hline
\end{tabular}

Médias seguidas por letras diferentes diferem estatisticamente entre si pelo Teste de Tukey a 5,0\% de probabilidade.

Para o teor de vermelho (a*) em que foi observado interação sexo $\mathrm{x}$ idade significativa $(\mathrm{P}<0,05)$ constatou-se que carne de codornas fêmeas é mais avermelhada em relação a carne de codornas machos. Em comparação com outras aves alternativas destaca-se que a carne de avestruz apresenta valores em relação à cor variando de $27,35 \leq \mathrm{L}^{*} \leq$ 37,$5 ; 13,65 \leq \mathrm{a}^{*} \leq 21,60$; e $0,06 \leq \mathrm{b}^{*} \leq$ 5,87 (HOFFMAN, 2008). Comparando os parâmetros descritos para a carne de avestruz com o obtido neste trabalho observa-se que a carne de codornas tende a apresentar maior luminosidade $\left(L^{*}\right)$ e teor de amarelo $\left(b^{*}\right)$ que a de avestruz, no entanto menor teor de vermelho $\left(\mathrm{a}^{*}\right)$, assim, evidencia-se que a carne de codorna possui uma aparência mais luminosa e clara que a de avestruz. Resultados da literatura, em geral, indicam não haver influência do sexo sobre os teores de vermelho da carne (FANATICO et al., 2005; LONERGAN et al., 2003; SANTOS et al., 2005; SOUZA, 2004). Estudos realizados por Santos et al. (2005) avaliando a coloração de carne de peito de linhagens comerciais de frango de corte e aves caipiras apresentaram valores médios de teor de vermelho $\left(\mathrm{a}^{*}\right)$ de 2,66 e 3,44, respectivamente. A carne de codornas, deste trabalho, apresentou valores médios de 10,67 evidenciando uma cor com tonalidade mais escura na mesma.

A idade de abate de 42 dias foi significativamente melhor $(\mathrm{P} \leq 0,05)$ para peso corporal, peso de carcaça quente, peso de carcaça resfriada, peso de peito e peso de pernas (Tabela 2). Isto em função das aves ainda apresentarem um crescimento corporal expressivo nessa fase, o que promove maior peso corporal, peso da carcaça e peso dos cortes. Não foi observado efeito $(\mathrm{P}>0,05)$ para as características de rendimento de carcaça e cortes nas diferentes idades de abate, 35 ou 42 dias. 
Os animais abatidos aos 35 ou aos 42 dias de idade apresentaram rendimento de carcaça resfriada de $79,95 \%$ e $80,48 \%$ e rendimento de peito de $27,73 \%$ e $27,88 \%$, respectivamente. Oliveira \& Escocard (2010), ao avaliarem o efeito da idade de abate para codornas japonesas, observaram $61,00 \%$ e $63,22 \%$ de rendimento de carcaça e $23,98 \%$ e $26,36 \%$ para rendimento de peito para as idades de 35 e 49 dias, respectivamente. Sugerindo assim que codornas européias possuem maior rendimento de carcaça em relação às codornas japonesas.

Tabela 2. Rendimento e pesos, de carcaça e cortes de carcaça de codornas européias, machos e fêmeas, abatidas aos 35 e 42 dias

\begin{tabular}{|c|c|c|c|c|c|}
\hline \multirow{2}{*}{ Parâmetro } & \multicolumn{2}{|c|}{ Idade de abate } & \multicolumn{2}{|c|}{ Sexo } & \multirow{2}{*}{$\mathrm{CV}(\%)$} \\
\hline & 35 dias & 42 dias & Macho & Fêmea & \\
\hline Peso corporal (g/ave) & $212,44 \pm 22,77^{b}$ & $240,42 \pm 21,12^{a}$ & $222,04 \pm 27,17$ & $230,82 \pm 24,45$ & 9,75 \\
\hline Peso carcaça quente (g/ave) & $170,04 \pm 21,18^{\mathrm{b}}$ & $193,33 \pm 16,09^{\mathrm{a}}$ & $181,14 \pm 24,93$ & $182,23 \pm 19,26$ & 10,63 \\
\hline $\begin{array}{l}\text { Rendimento de carcaça } \\
\text { quente }(\%)\end{array}$ & $79,95 \pm 3,23$ & $80,48 \pm 2,60$ & $81,46 \pm 2,78^{\mathrm{a}}$ & $78,98 \pm 2,53^{\mathrm{b}}$ & 3,38 \\
\hline $\begin{array}{l}\text { Peso carcaça resfriada } \\
\text { (g/ave) }\end{array}$ & $165,78 \pm 19,70^{b}$ & $188,29 \pm 15,60^{\mathrm{a}}$ & $176,16 \pm 23,85$ & $177,91 \pm 18,10$ & 10,28 \\
\hline $\begin{array}{l}\text { Rendimento de carcaça } \\
\text { resfriada }(\%)\end{array}$ & $77,98 \pm 2,45$ & $78,39 \pm 2,59$ & $79,24 \pm 2,12^{\mathrm{a}}$ & $77,13 \pm 2,44^{\mathrm{b}}$ & 2,99 \\
\hline Peso do peito (g/ave) & $59,05 \pm 8,34^{\mathrm{b}}$ & $66,94 \pm 6,06^{\mathrm{a}}$ & $63,41 \pm 9,32$ & $62,58 \pm 7,20$ & 11,84 \\
\hline Rendimento de peito (\%) & $27,73 \pm 1,56$ & $27,88 \pm 1,65$ & $28,50 \pm 1,47^{\mathrm{a}}$ & $27,12 \pm 1,42^{\mathrm{b}}$ & 5,32 \\
\hline Peso de pernas (g/ave) & $41,23 \pm 4,73^{\mathrm{b}}$ & $45,55 \pm 4,53^{\mathrm{a}}$ & $42,81 \pm 6,07$ & $43,96 \pm 3,90$ & 10,79 \\
\hline Rendimento de pernas (\%) & $19,40 \pm 0,78$ & $18,95 \pm 1,05$ & $19,25 \pm 0,89$ & $19,10 \pm 1,00$ & 4,83 \\
\hline
\end{tabular}

O peso de pernas foi significativamente $(\mathrm{P} \leq 0,05)$ maior para a idade de 42 dias devido ao maior tamanho das aves, no entanto para o rendimento de pernas não houve efeito da idade de abate $(\mathrm{P}>0,05)$. Móri et al. (2005) estudando diferentes grupos genéticos de codornas machos abatidos aos 42 dias de idade, encontraram rendimento médio de pernas de $23,77 \%$, resultados maiores que os obtidos neste estudo em que a média do rendimento de pernas de machos foi de 19,40 e $18,95 \%$, para 35 e 42 dias de idades ao abate, respectivamente.

$\mathrm{O}$ sexo influenciou significativamente $(\mathrm{P} \leq 0,05)$ as características de rendimento de carcaça quente, rendimento de carcaça resfriada e rendimento de peito, sendo que os machos apresentam maiores médias. Silva et al. (2003) estudando o efeito da nutrição e do sexo sobre o rendimento de carcaça de codornas de corte aos 42 dias de idade demonstraram que, apesar do maior peso das fêmeas, os machos apresentam maior rendimento de carcaça, sendo $72,2 \%$ para machos e $68,4 \%$ para fêmeas, provavelmente em virtude do maior desenvolvimento do aparelho reprodutivo das fêmeas a essa idade. Houve efeito $(\mathrm{P}<0,05)$ da idade das codornas, para a característica de $\mathrm{pH}$ antes do resfriamento (Tabela 3), em que as aves com 35 dias de idade abate, obtiveram valores de $\mathrm{pH}$ mais altos em relação às aves abatidas aos 42 dias de idade. Os valores de $\mathrm{pH}$ são dependentes do glicogênio armazenado 
no músculo o qual é altamente influenciado pela atividade locomotora e aos fatores pré-abate. Esta diferença pode ser explicada por uma depleção mais rápida do glicogênio após o abate e produção de ácido lático nas codornas de idade mais avançada (GENCHEV et al., 2008).

Tabela 3. Parâmetros de qualidade da carne em codornas européias, machos e fêmeas, abatidas aos 35 e 42 dias

\begin{tabular}{lccccc}
\hline \multirow{2}{*}{ Parâmetro } & \multicolumn{2}{c}{ Idade de abate } & \multicolumn{2}{c}{ Sexo } & \multirow{2}{*}{ CV $(\%)$} \\
\cline { 2 - 5 } & 35 dias & 42 dias & Macho & Fêmea & \\
\hline pH após toalete & $5,96 \pm 0,13^{\mathrm{a}}$ & $5,86 \pm 0,13^{\mathrm{b}}$ & $5,90 \pm 0,14$ & $5,92 \pm 0,13$ & 2,18 \\
pH 24h 'post mortem' & $5,83 \pm 0,12$ & $5,79 \pm 0,10$ & $5,76 \pm 0,11^{\mathrm{b}}$ & $5,87 \pm 0,08^{\mathrm{a}}$ & 1,68 \\
CRA (\%) & $22,53 \pm 2,23$ & $22,68 \pm 1,56$ & $22,82 \pm 2,36$ & $22,40 \pm 1,33$ & 8,63 \\
Luminosidade (L*) & $52,80 \pm 1,30$ & $51,81 \pm 2,78$ & $52,10 \pm 2,32$ & $52,51 \pm 2,57$ & 4,65 \\
Teor de amarelo (b*) & $7,35 \pm 1,22$ & $7,31 \pm 1,52$ & $7,17 \pm 1,46$ & $7,49 \pm 1,28$ & 19,17 \\
PPC (\%) & $5,58 \pm 1,77$ & $6,56 \pm 1,43$ & $6,03 \pm 2,00$ & $6,12 \pm 1,29$ & 26,90 \\
Maciez objetiva (kgf/g) & $1,26 \pm 0,29$ & $1,32 \pm 0,42$ & $1,20 \pm 0,24$ & $1,39 \pm 0,43$ & 26,87 \\
\hline
\end{tabular}

$\mathrm{CRA}=$ capacidade de retenção de água; $\mathrm{PPC}=$ perda de peso por cocção.

Médias seguidas por letras diferentes diferem estatisticamente entre si pelo Teste $\mathrm{F}$ a $5 \%$ de probabilidade.

Foi observado efeito $(\mathrm{P} \leq 0,05)$ do sexo das codornas de corte, para a característica $\mathrm{pH} 24$ horas 'post mortem' (Tabela 3), em que os machos apresentaram valores de $\mathrm{pH}$ mais baixos, indicando que as reservas de glicogênio dos machos podem ser superiores em relação aos valores das fêmeas (DRBOHLAV \& DRBOHLAVOVA, 1987), ocorrendo desta forma maior gasto de glicogênio e maior produção de ácido lático. Contudo mesmo havendo a diferença de valores de $\mathrm{pH} 24$ horas 'post mortem' entre machos e fềmeas apresentados neste trabalho estes valores não foram abaixo dos descritos na literatura para caracterização de carne de frangos como PSE (pálida, mole, exsudativa). $\mathrm{O}$ declínio do $\mathrm{pH}$ muscular durante o período 'post mortem' é determinado pelas condições fisiológicas do músculo no momento do pré-abate, relacionando-se diretamente com a formação de ácido lático, ou mais especificadamente com a capacidade do músculo em produzir energia na forma de adenosina trifosfato-ATP. Após o abate ocorre consumo das reservas musculares de ATP e glicose ocasionando a queda do $\mathrm{pH}$, em condições de estresse os carboidratos são decompostos por meio de processo anaeróbicos para síntese de ATP, formando pequenas quantidades de ATP e altas concentrações de ácido lático resultando em $\mathrm{pH}$ mais baixos (SOUZA, 2004; RAMOS \& GOMIDE, 2007; PINTO, 2008).

A carne de peito de frango para animais que não tiveram um estresse pré-abate apresenta $\mathrm{pH}$ final que varia de 5,7 a 5,9, resultando em carne normal (SOUZA, 2004). A média do $\mathrm{pH}$ da carne de peito de codornas deste experimento foi de 5,76 e 5,87 para machos e fêmeas respectivamente, verificando-se valores que se enquadram na faixa de $\mathrm{pH}$ estipulada para carne normal. 
Para capacidade de retenção de água (CRA), perda de peso por cocção (PPC), luminosidade e teor de amarelo (Tabela 3) não foram observadas diferenças significativas $(\mathrm{P} \geq 0,05)$ entre as idades de abate ou entre os sexos. Segundo Dabés (2001), a menor capacidade de retenção de água implica em perdas do valor nutritivo por meio do exudato eliminado e resulta em carne mais seca e, consequentemente, menos macia.

A maciez da carne é composta por um grupo de propriedades, no entanto duas estruturas do músculo são diretamente responsáveis pela sua maciez: o tecido conectivo e as fibras musculares. A maciez da carne é considerada a característica organoléptica de maior influência na aceitação da carne por parte dos consumidores. Entre os fatores que influenciam a maciez da carne, destacam-se a genética, a raça, a idade ao abate, o sexo, a alimentação e os tratamentos 'post mortem' (RAMOS \& COMIDE, 2007; ALVES, 2007; TORRES FILHO, 2012).

A maciez objetiva não apresentou diferença $(P \geq 0,05)$ para as idades de abate ou para o sexo das codornas de corte. Bressan (1998) ao estudar o efeito da temperatura de resfriamento sobre o desenvolvimento das reações químicas 'post-mortem' da carne de frangos de corte observou valores médios de $3,48 \mathrm{kgf}^{-1}$. Neste estudo foram observados valores médios de 1,29kgf $\mathrm{g}^{-1}$, sugerindo, que a carne de codornas é mais macia que a carne de frangos de corte. Takahashi (2008) obteve resultados médios de $1,41 \mathrm{kgf} \mathrm{g}^{-1}$ para a força de cisalhamento da carne de peito de frango de matrizes pesadas desossadas após o estabelecimento do "rigor mortis", valor próximo aos obtidos neste estudo.

A partir dos resultados obtidos neste experimento, conclui-se que fềmeas abatidas aos 42 dois dias de idade possuem uma carne com tonalidade mais avermelhada e que os animais abatidos a esta idade possuem melhor desempenho. $\mathrm{O}$ sexo influenciou as características de rendimento de carcaça quente, carcaça resfriada e peito sendo que os machos apresentaram os melhores rendimentos.

Codornas abatidas aos 35 dias possuem $\mathrm{pH}$ após toalete maiores que as abatidas aos 42 dias de idade, enquanto para $\mathrm{pH}$ $24 \mathrm{~h}$ 'post mortem' machos possuem valores de $\mathrm{pH}$ menores.

Portanto para codornas de corte recomenda-se o abate aos 42 dias de idade para obtenção desempenhos satisfatórios, uma vez que os parâmetros de qualidade da carne mantiveram-se dentro dos padrões adequados.

\section{AGRADECIMENTOS}

Os autores agradecem o apoio financeiro recebido da CAPES, CNPq e Fapemig.

\section{REFERÊNCIAS}

ALVES, D.D.; MANCIO, A.B.

Tenderness of bovine meat: a review.

Revista da Faculdade de Zootecnia, Veterinária e Agronomia, v.14, p.193216, 2007.

AMERICAN MEAT SCIENCE ASSOCIATION - AMSA. Research guidelines for cookery sensory and instrumental tenderness measurement of fresh meat. Chicago, 1995. 
BRESSAN, M.C. Efeito dos fatores pré e pós-abate sobre a qualidade da carne de peito de frango. 1998. 201p. Tese (Doutorado em Tecnologia de Alimentos) - Faculdade de Engenharia de Alimentos, Universidade Estadual de Campinas, Campinas.

CORRÊA, G.S.S.; SILVA, M.A.; CORREA, A.B.; FONTES, D.O.; SANTOS, G.G.; TORRES, R.A.; DIONELLO, N.J.L.; FREITAS, L.S.; FRIDRICH, A.B. Crude protein requirements for EV1 meat type quail during the growing period. Arquivo Brasileiro de Medicina Veterinária e Zootecnia, v.59, n.5, p.1278-1286, 2007.

DABÉS, A.C. Propriedades da carne fresca. Revista Nacional da Carne, v.25, n.288, p.32-40, 2001.

DRBOHLAV, V.; DRBOHLAVOVA, $D$. The effect of storage on some properties characterizing the quality of broiler meat. Food industry Science, v.3, p.25-29. 1987.

FANATICO, A.C.; CAVITT, L.C.; PILLAI, P.B.; EMMERT, J.L.; OWENS, C.M. Evaluation of slowergrowing broiler genotype grown with and without outdoor access: meat quality. Poultry Science, v.84, p.17851790, 2005.

FRIDRICH, A.B.; VALENTE, B.D.; FELIPE-SILVA, V.P.; SILVA, M.A., CORREAA, G.S.S.; FONTES, D.O.; FERREIRA, I.C. Crude protein requirement for European quails during the growing period. Arquivo Brasileiro de Medicina Veterinária e Zootecnia, v.57, n.2, p.261-265, 2005.
GARCIA, E.A. Codornas para a produção de carne. In: SIMPÓSIO INTERNACIONAL DE COTURNICULTURA, Lavras, 1. 2002, Lavras. Anais... Lavras: Universidade Federal de Lavras, 2002. p.97-108.

GENCHEV, A.; MIHAYLOVA, G.; RIBARSKI, S.; PAVLOV, A.; KABAKCHIEV, M. Meat quality and composition in japanese quails. Trakia Jouornal of Sciences, v.6, n.4, p.72-82, 2008.

GENCHEV, A.G.; RIBARSKI, S.S.; AFANASJEV, G.D.; BLOHIN, G.I. Fattening capacities and meat quality of Japanese quails of Faraon and White English breeds. Journal Central European Agriculture, v.6, n.4, p.501505, 2005.

HAMM, R. Biochemistry of meat hydratation. Advances in Food Research, v.10, n.2, p.335-443, 1960.

HOFFMAN, L.C. The yield and nutritional value of meat from African ungulates, camelidae, rodents, ratites and reptiles. Meat Science, v.80, p.94100, 2008.

HONIKEL, K.O. Influence of chilling on meat quality attributes of fast glycolysing pork muscles. In:

TARRANT, P.V.; EIKELENBOOM, G.; MONIN, G. (Eds.). Evaluation and control of meat quality in pigs.

Dordrecht: Martinius Nijhoff, 1987. p.273-283.

LONERGAN, S.M.; DEEB, N.; FEDLER, C.A.; LAMONT, S.J. Breast meat quality and composition in unique chicken populations. Poultry Science, v.82, p.1990-1994, 2003. 
MÓRI, C.; GARCIA, E.A.; PAVAN, A.C.; PICCININ, A.; PIZZOLANTE, C.C. Performance and carcass yield of four quail genetic groups selected for meat production. Revista Brasileira de Zootecnia, v.34, n.3, p.870-876, 2005.

OLIVEIRA, N.T.E.; ESCOCARD, C.P.S. Evaluation of body weight and carcass traits of males Japanese quails by slaughter age. Revista Agrarian, v.3, n.7, p.78-83, 2010.

OLIVEIRA, N.T.E.; SILVA, M.A.; SOARES, R.T.R.N.; FONSECA, J.B.; THIEBAUT, J.T.L. Crude Protein and Metabolizable Energy Requirements for Japanese Quails Reared for Meat Production. Revista Brasileira de Zootecnia, v.31, n.2, p.675-686, 2002a.

OLIVEIRA, E.G.; ALMEIDA, M.I.M.; MENDES, A.A.; VEIGA, N.; DIAS, K. Growth performance of meat quails of both sexes fed diets with four protein levels. Arquivo Brasileiro de Medicina Veterinária e Zootecnia, v.7, n.2, p.75-80, 2002 b.

PINTO, P.S. de A. Inspeção e higiene de carnes. Viçosa, MG: Universidade Federal de Viçosa, 2008. 320p.

RAMOS, E.M.; GOMIDE, L.A.M. de Avaliação da qualidade de carnes: fundamentos e metodologias. Viçosa, MG: Universidade Federal de Viçosa, 2007.

ROSTAGNO, H.S.; ALBINO, L.F.T.; DONZELE, J.L.; GOMES, P.C.; OLIVEIRA, R.F.; LOPES, D.C.; FERREIRA, A.S.; BARRETO, S.L.T. Tabelas Brasileiras para aves e suínos: composição de alimentos e exigências nutricionais. Viçosa, MG: Universidade Federal de Viçosa, 2005. $186 \mathrm{p}$.
SANTOS, A.L.; SKOMURA, N.K.; FREITAS, E.R.; FORTES, C.M.L.S; CARRILHO, E.N.V.M.; FERNANDES, J.B.K. Growth, performance, carcass yield and meat quality of three broiler chickens strains. Revista Brasileira de Zootecnia, v.34, n.5, p.1589-1598, 2005.

STATISTICAL ANALYSES SYSTEM. User's guide. Cary: SAS Institue INC., 1996.

SILVA, J.H.V. Tabelas para codornas japonesas e européias - Tópicos Especiais, Composição de Alimentos e Exigências Nutricionais. Jaboticabal, SP: FUNEP, 2009. 107p.

SILVA, J.H.V.; ANDRADE, I.S.; MELO, D.A.; SILVA, E.L.da; JORDÃO FILHO, J.; RIBEIRO, M.L.G.; SANTOS, J.de L.; ROCHA, M.do R. de F.; COSTA, F.G.P. Efeitos do plano de nutrição e do sexo sobre o rendimento de carcaça de codornas tipo carne. In: REUNIÃO ANUAL DA SOCIEDADE BRASILEIRA DE ZOOTECNIA, 40., 2003, Santa Maria. Anais... Santa Maria: Sociedade Brasileira de Zootecnia, 2003.

SOUZA, X.R. Características de carcaça, qualidade de carne $e$ composição lipídica de frangos de corte criados em sistemas de produção caipira e convencional. 2004. 334. Tese (Doutorado em Zootecnia) Universidade Federal de Lavras, Lavras.

TAKAHASHI, S.E.; MENDES, A.A.; KOMIYAMA, C.M.; MOREIRA, J.; ALMEIDA PAZ, I.C.L.; GARCIA, R.G.; QUINTERO, R.R.; BALOG NETO, A.; SOUZA, H.B.A.; LEONEL, F.R. Effect of environmental temperature on meat quality of broiler chickens. PUBVET Publicações em Medicina Veterinária e Zootecnia, v.2, p.1-15, 2008. 
TORRES FILHO, R.A. Efeito de linhagem, de sexo e de nível de proteína na dieta sobre a qualidade de carne de codornas de corte. 2012. 96. Dissertação (Mestrado em Ciência e Tecnologia de Alimentos) Universidade Federal de Viçosa, Viçosa.

Van LAACK, R.L.J.M.; LIU, C.H.; SMITH, M.O.; LOVEDAY, H.D. Characteristics of pale, soft, exudative broiler breast meat. Poultry Science, v.79, n.7, p.1057-1061, 2000.

VIEIRA, S.L. Considerações sobre as características de qualidade de carne de frango e fatores que podem afetála. Porto Alegre, 1999. Disponível em: $<$ http://www.sbz.org.br/eventos/PortoAl egre/homepagesbz /Sergio.htm>. Acesso em: 17 out. 2004
VELOSO, R..C.; DRUMOND, E.S.C.; VASCONCELOS, R.C.; PIRES, A.V.; FASSANI, E.J.; CRUZ, V.A.R.

Proteína bruta e energia metabolizável para codornas de corte: 1 - Fase inicial. In: IV SIMPÓSIO INTERNACIONAL E III CONGRESSO BRASILEIRO DE CODORNAS DE CORTE, 2010, Lavras: Anais... Lavras, 2010.

VELOSO, R.C.; PIRES, A.V.; TIMPANI, V.D.; DRUMOND, E.S.C.; GONÇALVES, F.M.; FARIA FILHO, D.E. Protein and metabolizable energy on a meat quail line. Acta Scientiarum. Animal Sciences, v.34, n.2, p.169-174, 2012 .

Data de recebimento: 19/09/2013

Data de aprovação: 13/02/2014 